\title{
Experimental Investigation of the Flame Propagation and Flashback Behavior of a Green Propellant Consisting of $\mathrm{N}_{2} \mathrm{O}$ and $\mathrm{C}_{2} \mathrm{H}_{4}$
}

\author{
Lukas Werling, Felix Lauck, Dominic Freudenmann, Nicole Röcke, Helmut Ciezki and Stefan Schlechtriem \\ German Aerospace Center (DLR), Institute of Space Propulsion, Im Langen Grund, Hardthausen 74239, Germany
}

\begin{abstract}
Regarding the research on alternatives for monopropellant hydrazine, several so called green propellants are currently under investigation or qualification. Aside others, the DLR Institute of Space Propulsion investigates a $\mathrm{N}_{2} \mathrm{O} / \mathrm{C}_{2} \mathrm{H}_{4}$ premixed green propellant. During the research activities, flashback from the rocket combustion chamber into the feeding system has been identified as a major challenge when using the propellant mixture. This paper shows the results of ignition experiments conducted in a cylindrical, optical accessible ignition chamber. During the ignition and flame propagation process, pressure, temperature and high-speed video data were collected. The high speed video data were used to analyze the flame propagation speed. The obtained propagation speed was about $20 \mathrm{~m} / \mathrm{s}$ at ignition, while during further propagation of the flame speeds of up to $120 \mathrm{~m} / \mathrm{s}$ were measured. Additionally, two different porous materials as flame arresting elements were tested: Porous stainless steel and porous bronze material. For both materials Peclet numbers for flashback were derived. The critical Peclet number for the sintered bronze material was around 20, while for the sintered stainless steel the critical Peclet number seems to be larger than 40. Due to the test results, sintered porous materials seem to be suitable as flashback arresters.
\end{abstract}

Key words: Green rocket propellants, ignition, flame flashback, $\mathrm{N}_{2} \mathrm{O}, \mathrm{C}_{2} \mathrm{H}_{4}$, premixed gases, flashback arresters, porous materials.

\section{Introduction}

Since decades, hydrazine is used as a monopropellant to power satellites, landers or planetary probes [1]. The propellant offers good performance (vacuum $I_{\mathrm{sp}}$ up to $240 \mathrm{~s}$ ), is long term storable and easy to decompose via catalyst. Further advantages are the cold start capability of hydrazine thrusters and the low risk of unwanted decomposition or explosion. Numerous years of experience with reliable hydrazine thrusters create space systems which are able to reach the edges of our solar system. A remarkable example is the Voyager 1 probe, which re-ignited its hydrazine thrusters after more than 30 years in the harsh environment of interplanetary space $[2,3]$. Nevertheless hydrazine and its derivatives have a very concerning attribute: They are highly carcinogenic and

Corresponding author: Lukas Werling, Dipl.-Ing., research fields: green rocket propellants, rocket test facilities. toxic. Due to the high toxicity, complex safety measures are needed which result in high handling and transportation costs. Thus hydrazine was recently put on the REACH (Registration, Evaluation, Authorization and Restriction of Chemicals) list for substances with very high concern [4].

Due to those drawbacks of hydrazine the research on less or non-toxic propellants came in the focus of investigations across the world [5-7]. Several so called green propellants are currently under investigation or qualification: ADN-based monopropellants (LMP-103S, FLP-106) [8-10], HAN-based propellants (e.g. AF-M315E) [11-14], high concentrated $\mathrm{H}_{2} \mathrm{O}_{2}$ [15-18] and mixtures of $\mathrm{N}_{2} \mathrm{O}$ with different hydrocarbons, also known as nitrous oxide fuel blends [19-21].

Aside other propellants and propellant combinations, the DLR Institute of Space Propulsion investigates a $\mathrm{N}_{2} \mathrm{O} / \mathrm{C}_{2} \mathrm{H}_{4}$ premixed green propellant in an experimental combustion chamber. A major 
challenge during the research activities was the avoidance of a flame flashback at ignition of the propellant mixture. In case of a flashback, the flame propagates upstream the injection system to the feeding system of the combustor. This challenge must be met to assure a safe use of the propellant mixture. Thus the ignition and flame flashback behavior of the propellant has to be understood. To investigate the flame propagation and flashback processes, DLR set up an optical accessible ignition chamber. In the closed chamber the gaseous $\mathrm{N}_{2} \mathrm{O} / \mathrm{C}_{2} \mathrm{H}_{4}$ propellant mixture is ignited and the flame propagation is observed via high-speed camera.

This paper is structured as follows: Chapter 2 gives the theoretical background of the flame propagation process and describes flame flashback and quenching phenomena. A commonly used parameter to compare the different conditions under which a flame flashback occurs is the dimensionless Peclet number.

Chapter 3 describes the experimental setup and the experimental procedures which were used to conduct the tests. To investigate the behavior during ignition and flame propagation, a cylindrical, optical accessible combustion chamber was constructed and implemented in a test setup for premixed propellants. Furthermore several flame arresting elements (porous materials) were tested on their ability to prevent flame propagation from the ignition chamber into a secondary (flashback) chamber.

In Chapter 4 the test results are shown and discussed. During the flame propagation process, pressure, temperature and high-speed videos data were recorded. To test the quenching limits of the flashback arresters, the ignition pressure was raised step by step until a flashback occurred. For the used flame arresters the Peclet number under which flashback occurs were derived. The experimental data about the possible operation ranges should help design future flashback arresters. The pressure data and the high-speed images should later be used for comparison with numerical simulations of the combustion process inside a closed volume.

\section{Theoretical Background-Flame Propagation, Flashback and Quenching}

During ignition and flame propagation in a closed volume several effects influence the flame velocity and the flashback or quenching behavior of the flame. The following section describes the effects observed during the combustion tests and gives a general overview.

\subsection{Reaction Mechanism}

The overall chemical reaction for a stoichiometric $\mathrm{N}_{2} \mathrm{O} / \mathrm{C}_{2} \mathrm{H}_{4}$ mixture is given by:

$$
\begin{gathered}
6 \mathrm{~N}_{2} \mathrm{O}+\mathrm{C}_{2} \mathrm{H}_{4} \rightarrow 2 \mathrm{CO}_{2}+6 \mathrm{~N}_{2}+2 \mathrm{H}_{2} \mathrm{O} \\
\Delta \mathrm{H}_{r}^{0}=-1,812.6 \mathrm{~kJ} / \mathrm{mol}
\end{gathered}
$$

The heat of formation $\Delta H_{f}^{0}$ of the educts and products in Eq. (1) were taken from Ref. [22]. To calculate the laminar flame speed the software toolkit Cantera [23] and an reaction mechanism based on GRI3.0 [24] was used. The reaction mechanism was optimized and reduced by the Institute of Combustion Technology at DLR in Stuttgart. This mechanism predicts the laminar flame speed in good accordance to experiments [25].

\subsection{Flame Propagation in a Closed Volume}

The flame front in a closed volume moves with an average speed that is several times larger than the laminar flame speed. This is caused by the rapid expansion of the burned gases behind the flame front. Thus the observed flame propagation speed $S_{\text {ofp }}$ results from the laminar flame speed $S_{\mathrm{L}}$ and the expansion speed of the combustion products $S_{\text {exp }}$ :

$$
S_{\text {ofp }}=S_{L}+S_{\text {exp }}
$$

Using energy and mass conservation, for a one dimensional isobaric flame propagation, the expansion speed of the combustion products results in Ref. [26]:

$$
S_{\text {exp }}=\frac{\rho_{u}-\rho_{b}}{\rho_{b}} S_{L}
$$

Here $\rho_{\mathrm{u}}$ marks the density of the unburned mixture 
and $\rho_{b}$ is the density of the burned mixture. Due to high density changes across the flame front, the expansion speed of the combustion products is significantly higher than the laminar flame speed. Using Eqs. (2) and (3), the observed flame propagation speed results in:

$$
S_{\text {ofp }}=\frac{\rho_{u}}{\rho_{b}} S_{L}
$$

Depending on the geometry and pressure inside the combustion chamber, the flame propagation speed changes during the combustion process. For constant volume combustion in a spherical bomb, the laminar flame speed can be derived by the pressure development in the closed volume $p$ related to the initial pressure $p_{0}$, the change of burned mass fraction $Y=m_{\mathrm{b}} / m_{0}$, the radius of the spherical volume $R_{\mathrm{W}}$ and the isentropic coefficient $\kappa$ :

$$
S_{L}=\frac{R_{W}}{3}\left(1-(1-Y)\left(\frac{p_{0}}{p}\right)^{\frac{1}{\kappa}}\right)^{-\frac{2}{3}}\left(\frac{p_{0}}{p}\right)^{\frac{1}{\kappa}} \frac{d Y}{d t}
$$

A good overview of different approaches to determine the laminar flame propagation speed in a spherical, closed volume that can be found in the paper by Faghih and Chen [27].

\subsection{Flame Flashback}

Flame flashback in a premixed combustible mixture can generally be caused by two effects: In the first case the flow field in which the flame is located allows the flame to propagate upstream. In the second case the flame heats up an adjacent surface (e.g. the injector) and the hot surface causes ignition of the mixture upstream in the combustion chamber. Four general flashback mechanisms are distinguished:

(1) Flame flashback in the core flow

Here the flame speed is larger than the main flow speed and the flame can propagate contrary to the main flow.

(2) Flame flashback in the boundary layer

In this case the velocity gradient at the boundary layer is smaller than the temperature gradient caused by flame quenching effects. So the flame speed is larger than the flow speed at a distinct distance from the wall. In this zone the flame can propagate upstream.

(3) Flame flashback caused by combustion instabilities

Due to pressure oscillations in the combustion chamber, the flame can be pushed forth and back. If the instability in the combustion chamber rises above the feeding line pressure, the flame can propagate backwards upstream in the injection system. During transient phases such as shut down or ignition of an engine or motor, this is the main reason for occurrence of flashback. To avoid flame flashback, caused by a pressure peak at ignition, the premixed flame has to be quenched by an appropriate flashback arrester.

(4) Flashback caused by swirls in the combustion chamber

If large eddies and recirculation zones are present in the combustion chamber, the vortexes can lead to a reversed flow of the combustible products. Due to heating of the injector walls, the quenching diameter decreases. Additionally the return flow influences the boundary layer, so the local flow speed is reduced and flame flashback is supported.

\subsection{Flame Quenching}

The dimensionless Peclet number is often used to describe if a flame is able to propagate through a small gap or hole. Several assumptions are made to derive the dependency of characteristic combustion parameters and the corresponding diameter or distance: The combustion products behave as an ideal gas, the pressure across the reaction zone is constant, the heat conduction is infinite fast, the flame structure is laminar and the walls are not heated by the flame. Via energy conservation, mass conservation and the ideal gas law, the critical quenching diameter $d_{q}$ can be written as Refs. [28, 29]:

$$
d_{q}=\frac{P e_{c} * \alpha_{u}}{S_{L}}
$$

Here $P e_{\mathrm{c}}$ is the critical Peclet number under which 
quenching occurs, $S_{\mathrm{L}}$ marks the laminar flame speed and $\alpha_{\mathrm{u}}$ is the thermal diffusivity of the unburned mixture:

$$
\alpha_{u}=\frac{\lambda_{u}}{\rho_{u} * c_{p, u}}
$$

In this equation, the heat conductivity of the unburned mixture is represented by $\lambda_{\mathrm{u}}$, the density of the unburned mixture by $\rho_{\mathrm{u}}$ and the specific heat capacity of the unburned mixture by $c_{\mathrm{p}, \mathrm{u}}$. In literature, the critical Peclet number varies widely with the used test setup and the corresponding quenching phenomena. Furthermore the wall material seems to play a role in defining the quenching distance. Different Peclet numbers are derived for:

(1) Head on quenching

For a propane/air mixture the critical Peclet number observed in experiments ranges from 3.8 for quenching at ceramic walls to $P e_{\mathrm{c}}=4.7$ for quenching at polished steel walls [30]. Boust et al. [31] obtained critical Peclet numbers of 2.6 for a steel obstacle.

(2) Side wall quenching

The critical Peclet number ranges from 5.6 for ceramic walls to 8.5 for polished steel walls, for a propane/air mixture [30]. During other experiments a Peclet number of 4.5 was derived [31].

(3) Quenching between parallel plates

For quenching between parallel plates, the critical distance seems to be 0.65 time the distance of the quenching diameter in circular ducts [32]. In a study of Jarosinsky [33] for wedged shaped channels the Peclet number was observed to be 42 , while the value for rectangular channels was 51. In a numerical study, Daou and Matalon [34] found the critical quenching distance in a two-dimensional channel corresponding to 15 times the flame thickness. This is equivalent to a Peclet number of 15 . It has to be considered that in the study of Daou and Matalon only conductive heat losses were simulated and the flow was assumed to be laminar and stationary (Poiseuille-flow).

(4) Quenching in circular ducts

Spalding [35] made a few assumptions about the reaction behavior and calculated a critical Peclet of 60.5 for quenching in ducts, while Zel'dovich found the critical Peclet number to be approximately 65 [28]. For porous materials the critical Peclet number seems to be in a range of $\pm 50 \%$ regarding the theoretical value of 60.5 [36, 37]. Despite the wide range of experimentally and numerically derived Peclet numbers, the quenching diameter generally scales with a characteristic flame length scale $\delta_{\mathrm{L}}$.

$$
\delta_{L}=\frac{\alpha_{u}}{S_{L}}
$$

A summary of the different Peclet numbers can be found in the textbook Combustion Phenomena by Jarosinski and Veyssiere [38].

\section{Experimental Setup and Test Procedure}

The experimental setup is located at the M11 test bench at DLR in Lampoldshausen. It consists of an adaptable feeding system for the gas supply, a mixing section and the test chambers. A simplified P\&ID of the feeding lines is shown in Fig. 1. On the right side of the instrumentation diagram, the gas supply tanks are shown. Downstream the tanks pressure regulators are situated to adjust the oxidizer or fuel pressure. Furthermore each feeding line is equipped with an automatic valve and pressure sensors. The pressure sensors are used to compare the manually adjusted pressure at the regulators with the pressure in the supply lines. Additionally the gas temperature is measured via Typ-K thermocouples. The pressure and temperature data are used to calculate the needed pressure of the second gas to obtain the wanted mixture ratio in the mixing chamber. The mixing chamber is separated to the ignition and flashback chamber via valves.

The test chamber itself consists of the ignition and the flashback chamber (Fig. 3). At the ignition chamber two pressure transducers (Kistler Typ 4045, 100 bar, P-ZK-01, P-ZK-02) and two type-K thermocouples (T-ZK-01, T-ZK-02) are mounted (Fig. $2)$. The flashback chamber is equipped with one 


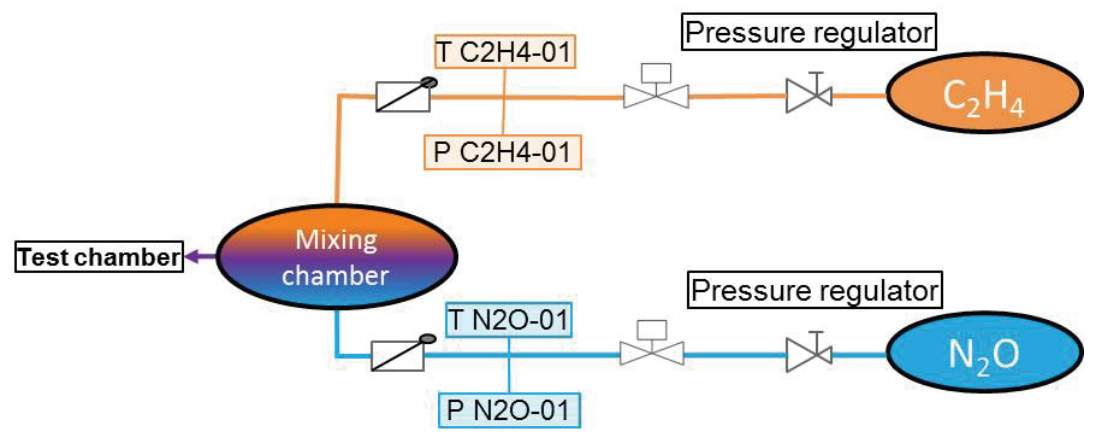

Fig. 1 P\&ID mixing section.

pressure sensor (Kistler Typ 4045, 100 bar, P-SK-01) and also a type-K thermocouple (T-SK-01).

During the test series, two different chamber configurations were used:

(1) Configuration A as shown in Fig. 2, with a glass window mounted at the ignition chamber. During those tests the high speed videos were recorded. Due to the pressure peaks during the ignition tests (see e.g. Fig. 16) the glass window could only be used up to an ignition pressure of approximately $1.8 \mathrm{bar}$. At higher pressure levels the glass did break. In configuration A the pressure sensors are connected to the chambers via $4 \mathrm{~mm}$ tubes with a length of $100 \mathrm{~mm}$.

(2) Configuration B with a steel plate instead of a glass window. By using a steel plate, the ignition pressure could be increased. For those tests, the pressure sensors of the ignition chamber (P-ZK-01 and P-ZK-02) were flush mounted to the steel plate to achieve a better resolution of the pressure peaks inside the ignition chamber.

The tips of the thermocouples are positioned 2-3 $\mathrm{mm}$ away from the wall inside of the ignition chamber. The data acquisition rate of the pressure sensors is 50 $\mathrm{kHz}$, the thermocouples are recorded with $100 \mathrm{~Hz}$. Due to the slow response time of the thermocouples they are only used for detection of a flashback. The signals of the thermocouples and pressure transducers are amplified via Dewetron (DAQP-STG) signal amplifiers. The measurement system consists of a Jäger Adwin Pro II processor with corresponding modules for signal acquisition and valve controlling.
To ignite the gaseous mixture, a standard car spark plug was used. The inner diameter of the ignition chamber is $25 \mathrm{~mm}$, while the length of the cylindrical combustion volume is $93 \mathrm{~mm}$. The flashback chamber has an inner diameter of $12.5 \mathrm{~mm}$ and a length of 81 $\mathrm{mm}$.

The high speed camera used for the video acquisition of the ignition and combustion process is a Photron Fastcam SA1.1. The frame rate was set to $62,500 \mathrm{fps}$ with a resolution of $448 \times 176$ pixels. The flame front emits visible light due to the radiation of $\mathrm{CH}^{*}$ radicals (wavelength $431 \mathrm{~nm}$ ), thus no additional image amplifier was needed to visualize the flame front.

On the downstream side of the ignition chamber an automatic valve for venting the chamber prior and after each test is mounted. Additionally a connection for gas sampling is available. In Fig. 3 the sectional view of the chamber with a mounted porous material is shown.

\subsection{Test Procedure}

The process of test preparation and test conduction is shown in Figs. 4 and 5. Prior to the mixing of the gases, the intended mixture ratio was calculated. The real gas data were obtained from Refprop database [39], taking the given ambient temperature into account. For the mixing of the two gases an ideal gas mixing behavior was assumed.

The mixture ratio was set according to the following relationship: 


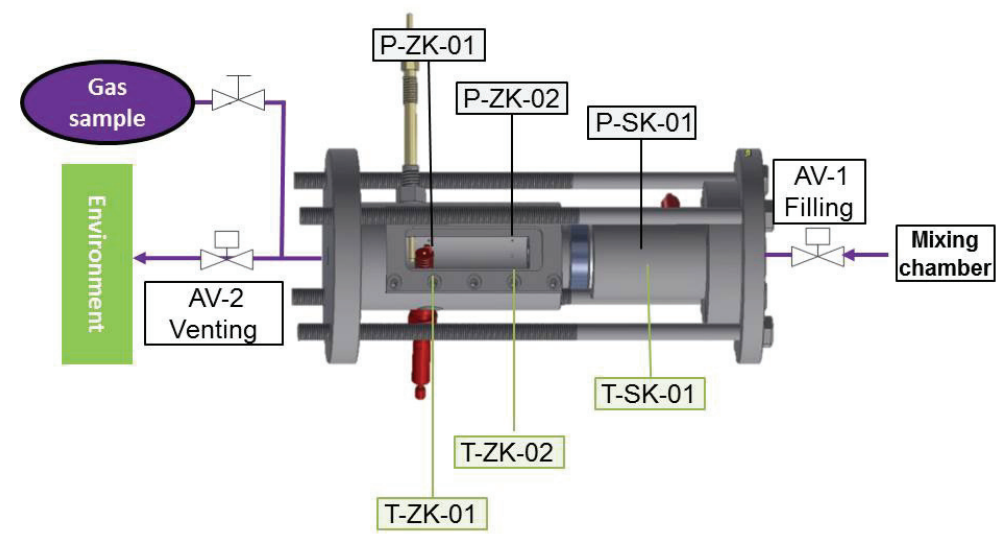

Fig. 2 P\&ID of test chamber.

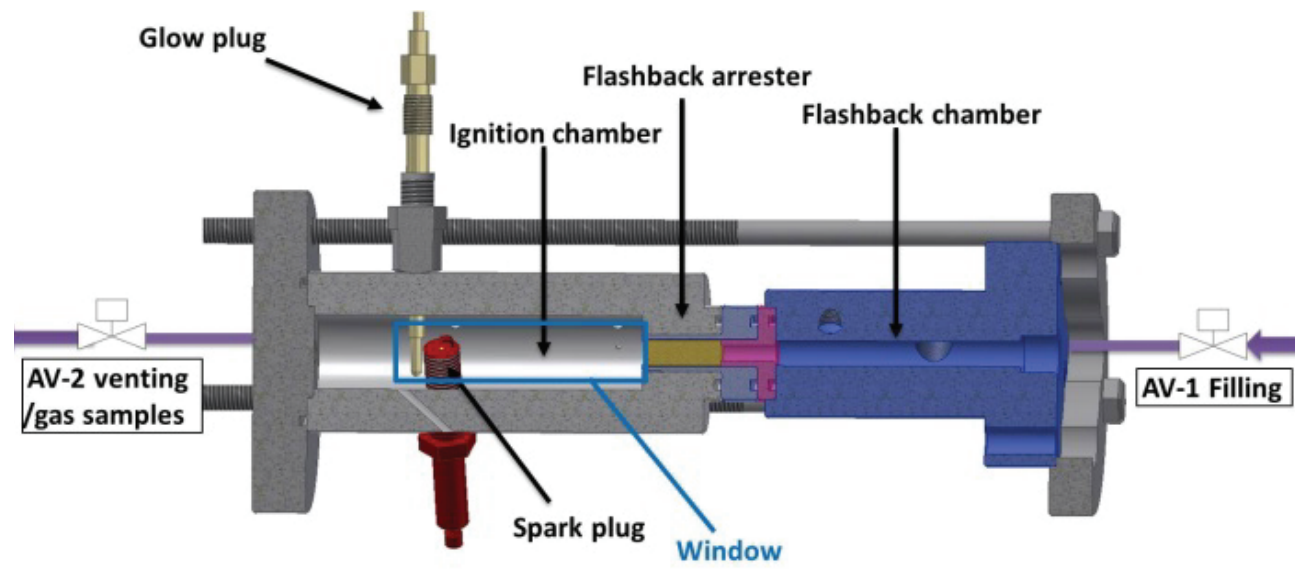

Fig. 3 Sectional view of the test chamber.

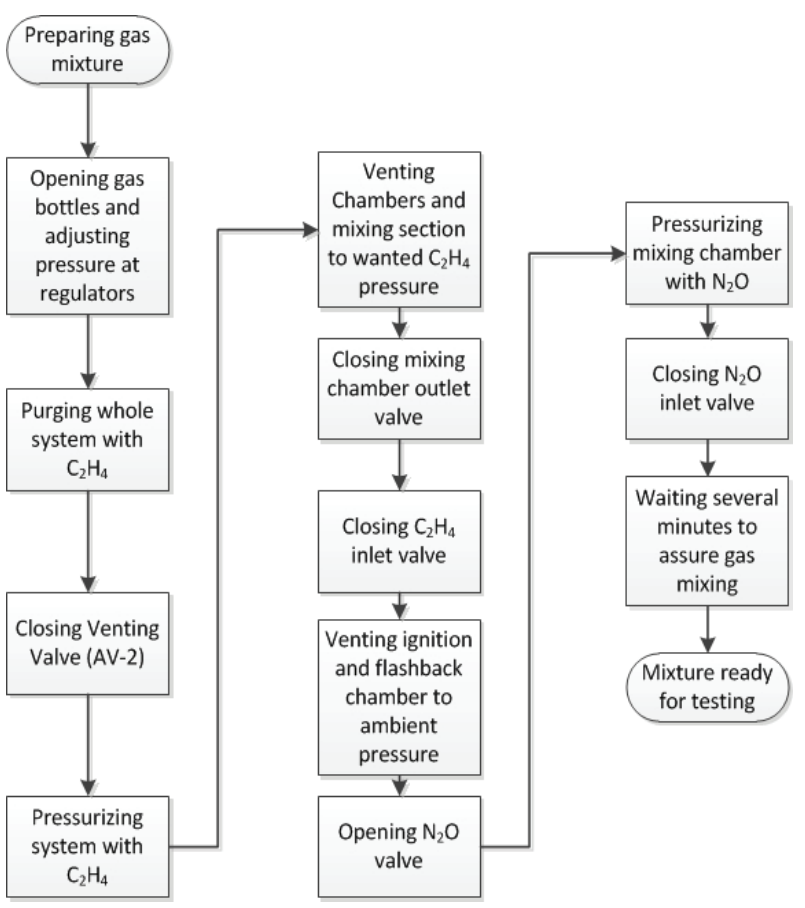

Fig. 4 Preparation of gas mixture.

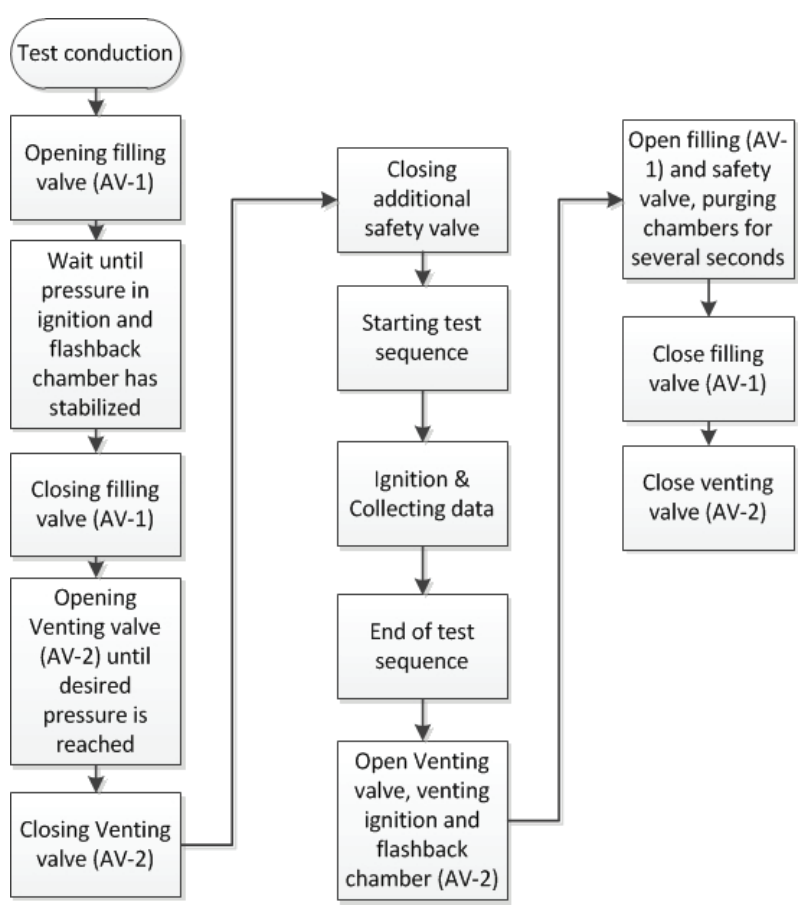

Fig. 5 Test conduction. 


$$
\begin{aligned}
\phi=\frac{R O F_{\text {stoich }}}{R O F}= & \frac{\left(m_{N_{2} O} / m_{C_{2} H_{4}}\right)_{\text {stoich }}}{\left(m_{N_{2} O} / m_{C_{2} H_{4}}\right)} \\
& =9.41 * \frac{m_{C_{2} H_{4}}}{m_{N_{2} O}} \\
& =9.41 * \frac{\rho_{C_{2} H_{4}}}{\rho_{N_{2} O}}
\end{aligned}
$$

The mass based stoichiometric mixture ratio (ROF) is 9.41. The volume of the mixing tank is identical for both gases, thus the mass ratio is equal to the density ratio. The first step during the test procedure was filling of the mixing vessel with $\mathrm{C}_{2} \mathrm{H}_{4}$ at an absolute pressure of 6 bar.

To clarify the calculation, the resulting densities and pressure levels are shown here for a gas temperature of $293 \mathrm{~K}$. At 6 bar and $293 \mathrm{~K}$ the density of $\mathrm{C}_{2} \mathrm{H}_{4}$ is $\rho_{\left(\mathrm{C}_{2} \mathrm{H}_{4}\right) 6 \mathrm{bar}}=7.17 \mathrm{~kg} / \mathrm{m}^{3}$. Assuming ideal gas mixing, the corresponding $\mathrm{N}_{2} \mathrm{O}$ density $\rho_{\mathrm{N}_{2} \mathrm{O}}$ was set to $10.5(\phi=0.9)$ times the $\mathrm{C}_{2} \mathrm{H}_{4}$ density at 6 bar. Thus $\mathrm{N}_{2} \mathrm{O}$ with a density of $75.29 \mathrm{~kg} / \mathrm{m}^{3}$ ( $\left.\rho_{\mathrm{N}_{2} \mathrm{O} \text {-wanted }}\right)$ had to be added to the mixing tank to obtain the desired mixture ratio. Furthermore the mass of $\mathrm{N}_{2} \mathrm{O}$ at 6 bar has to be subtracted, because filling of the mixing vessel only takes place if the $\mathrm{N}_{2} \mathrm{O}$ pressure is higher than the $\mathrm{C}_{2} \mathrm{H}_{4}$ pressure:

$$
\begin{gathered}
V_{\text {mix }} * \rho_{N_{2} O, \text { wanted }}+V_{\text {mix }} * \rho_{N_{2} O, 6 \text { bar }} \\
=V_{\text {mix }} * \rho_{N_{2} O, x b a r}
\end{gathered}
$$

The needed $\mathrm{N}_{2} \mathrm{O}$ density $\left(\rho_{\mathrm{N}_{2} \mathrm{O}, x \text { bar }}\right)$ was calculated and the corresponding pressure ( $x$ bar) was obtained from Refprop [39].

In this case the required $\mathrm{N}_{2} \mathrm{O}$ pressure was 35.9 bar. After the mixing tank was filled with $\mathrm{N}_{2} \mathrm{O}$, all valves were closed and the gases were allowed to mix for 5 minutes. Then the mixture was ready for testing.

Directly after filling and mixing the gases, a gas sample was collected. A second gas sample was taken at the end of a test run, when the mixing tank was nearly empty. Thus the variation of the mixture ratio and the possible pollution of the ignitable mixture with exhaust gases could be detected. The gas samples were analyzed with a previously calibrated gas chromatograph (Clarus 580 GC, Perkin Elmer) in the physical-chemical lab of DLR in Lampoldshausen.

Ignition tests were conducted in different configurations: With flashback-arresters mounted, without flashback arresters, with a quartz glass window at the side of the ignition chamber (configuration A) and with steel plates instead of the glass window toper form tests at higher pressure levels (configuration B). Pressure and temperature data were collected during all tests. The thickness of the glass window was $5 \mathrm{~mm}$, during the tests the window could withstand an ignition pressure of approximately 1.8 bar.

At the beginning of the experimental campaign, several tests were performed to adjust the shutter time of the high-speed camera and to assure proper function of the data acquisition system. During those tests no porous materials were mounted. The propagation speed of the flame depending on different ignition pressure was investigated during these test runs.

\subsection{Used Porous Materials/Flashback Arresters}

During the flashback tests, two different types of porous materials were used: SIKA-R sintered stainless steel filters (material 1.4404) and SIKA-B sintered bronze filters (material 2.1052) manufactured by GKN sinter metals. The materials were available in different lengths and filter grades. An overview of the used materials is given in Table 1 .

Different lengths and filter grades were chosen to investigate the influence of the length, the pore size

Table 1 Tested porous materials.

\begin{tabular}{llll}
\hline Material & $\begin{array}{l}\text { Filter grade } \\
{[40]}\end{array}$ & Length $(\mathrm{mm})$ & $\begin{array}{l}\text { Pore size }(\mathrm{mm}) \\
{[40,41]}\end{array}$ \\
\hline & 200 & 21 & 0.573 \\
SIKA-B, & 150 & 21 & 0.344 \\
2.1052 & 150 & 10.5 & 0.344 \\
& 100 & 21 & 0.232 \\
& 30 & 10.5 & 0.066 \\
SIKA-R, & 200 & 21 & 0.286 \\
1.4404 & 200 & 10.5 & 0.286 \\
& 200 & 7 & 0.286 \\
\hline
\end{tabular}



a Green Propellant Consisting of $\mathrm{N}_{2} \mathrm{O}$ and $\mathrm{C}_{2} \mathrm{H}_{4}$
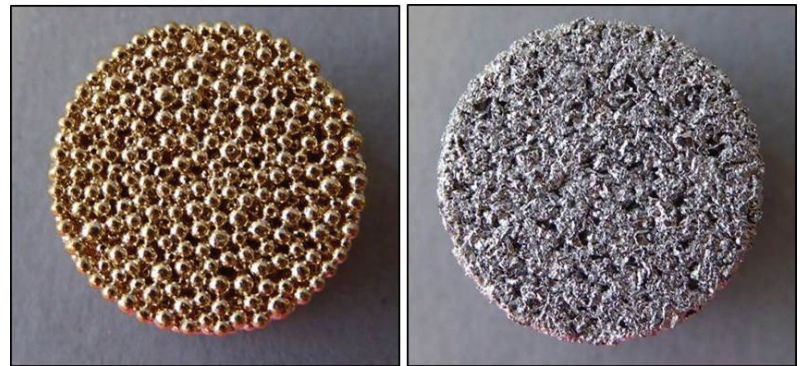

Fig. 6 Top view of SIKA B (left) and SIKA R (right) materials.

and to examine the influence of the filter material itself on its quenching ability. Pressure drop tests for the different porous materials were conducted prior to this study [42]. During those tests the SIKA-B material shows a reduced pressure drop for a similar pore size compared to the SIKA-R material. Additionally the SIKA-B material offers a higher heat conductivity, this could improve the quenching behavior. The porous materials were mounted in a fitting in between the ignition and the flashback chamber. Their outside was sealed with a shrinking tube and they were pressed into the fitting to avoid gap flows. A top view of two of the used porous materials is shown in Fig. 6.

During the flashback tests with the porous materials, the pressure was raised step by step-starting with ambient pressure - until a flashback occurred. In case of a flashback, the pressure was reduced again until no flashback occurred. After several (3-5) iterations of raising and lowering the ignition pressure, the critical point for flashback of the tested material was obtained.

\section{Results and Discussion}

\subsection{Tests without Flashback Arresters}

Typical frames of the flame propagation in the ignition chamber are shown in Fig. 7. The first image (frame 1) shows the ignition of the mixture caused by the spark plug.

Concerning the flame propagation and shape of the flame front, the following steps are observed during the experiments:
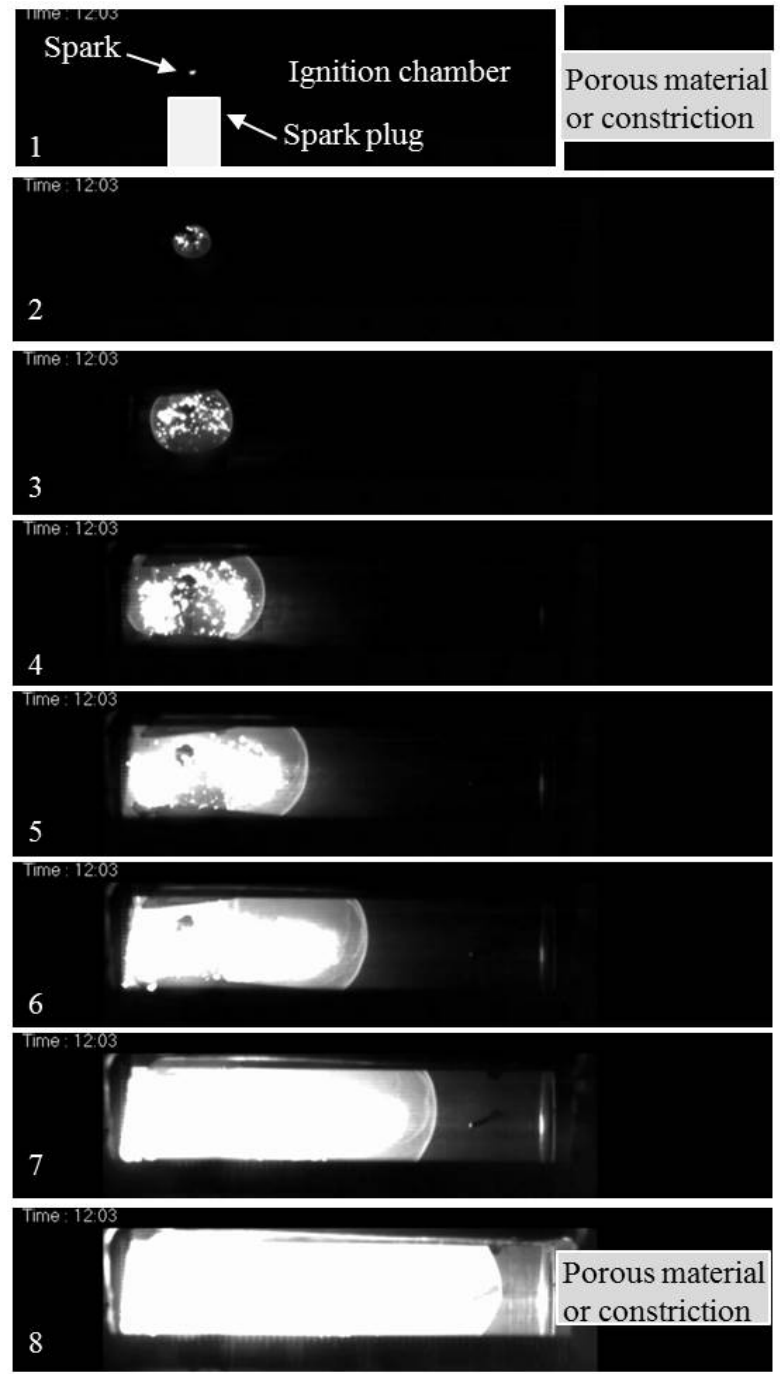

Fig. 7 High-Speed images of flame propagation $(62,500$ fps, despite in between 1 and 2 every 10th frame was taken; 1 bar ignition pressure).

(a) Ignition of the combustible mixture. The flame forms a sphere around the point of ignition (frame 1-3).

(b) The flame front approaches the walls of the chamber. The flame shape changes from spherical form to a "finger like" form. The tip of the flame is accelerated in axial direction (frame 4 and 5).

(c) The upper and lower flame edge touch the combustion chamber walls, there the flame is quenched. The reacting flame front moves horizontally (frame 6-8).

The observed effects and phases during ignition and flame propagation agree well with effects described in literature [43-45]. The glowing particles which are 
visible behind the flame front are soot particles caused by pollution of the ignition chamber due to previous ignition tests. Extensive cleaning of the chamber was only done after a full test series. In between the tests the chamber was only purged with gaseous mixture from the mixing chamber.

The video data were used to calculate the observed flame propagation speed. To derive the flame velocity the visible distance on the camera was correlated to the number of pixels on the image.

Fig. 8 shows the observed flame propagation speed during tests without flashback arresters at different ignition pressure levels. The propagation speed was calculated as:

$$
S_{o f p}=\frac{x_{i}-x_{i-1}}{t_{i}-t_{i-1}}
$$

where $x_{i}$ is the position and $t_{i}$ the time step of the flame in frame $i$. Furthermore a linear development of the flame speed in between $x_{i-1}$ and $x_{i}$ was assumed. So the corresponding $x$-position for the flame speed $\left(S_{\text {ofp }}\right)$ is in between position $x_{i}$ and position $x_{i-1}$, at $\left(x_{i}+x_{i-1}\right) / 2$.

The following behavior was observed during analysis of the flame propagation velocities:

(a) The flame starts to accelerate, beginning at the point of ignition. The acceleration seems to be linear until the flame tip reaches the middle $(x=$ flame position; $L=$ length from ignition point to constriction or porous material $x / L=0.5$ ) of the observed volume.

(b) After approximately half the length of the chamber $(x / L=0.5)$ a "velocity plateau" is reached. The flame travels at a constant speed. This effect is possibly caused due to a relatively constant surface area of the "finger shaped" flame front.

(c) At the right end of the chamber $(x / L=0.8)$ the flame speed slightly drops. Two effects might influence this behavior: First, the unsymmetrical position of the spark plug in the ignition chamber causes the flame front to propagate to the right (visible through window) and to the left. The left edge of the combustion chamber is reached earlier due to the position of the spark plug (see Fig. 3). When the left frame front reaches the wall, the flame surface is reduced significantly. Second the flow field ahead of the right flame front might interact with the walls at the constriction and slow down the flame tip.

(d) When the flame approaches the constriction in between the ignition and flashback chamber, it starts to accelerate sharply. This is caused by an acceleration of the subsonic flow at the constriction. The flame travels with the flow, if the flow is accelerated, the flame also speeds up. Fig. 9 shows the change of the flame shape while entering the connection in between the two chambers.

(e) For higher ignition pressures the average flame propagation speed seems to be larger. Despite the fact that laminar flame speed decreases with rising pressure [46], the mass consumption of the flame for a

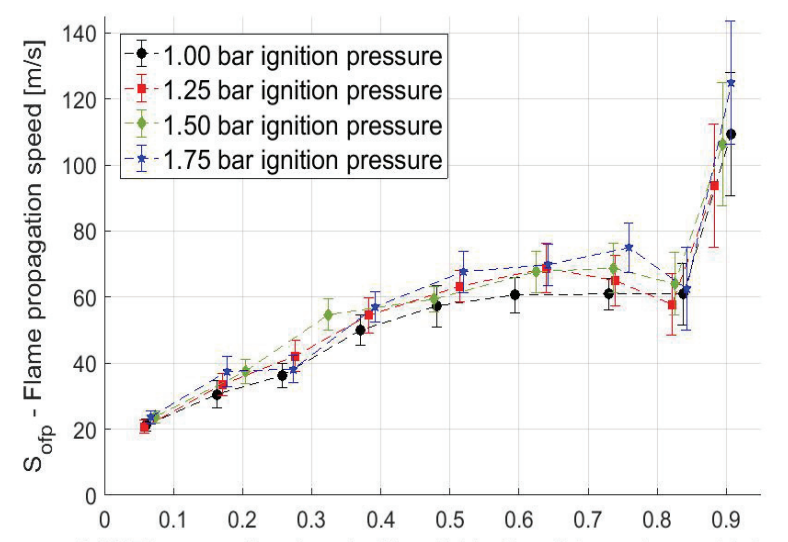

(x/L) Flame position from ignition divided by distance to constriction Fig. 8 Flame propagation speed for different ignition pressures.

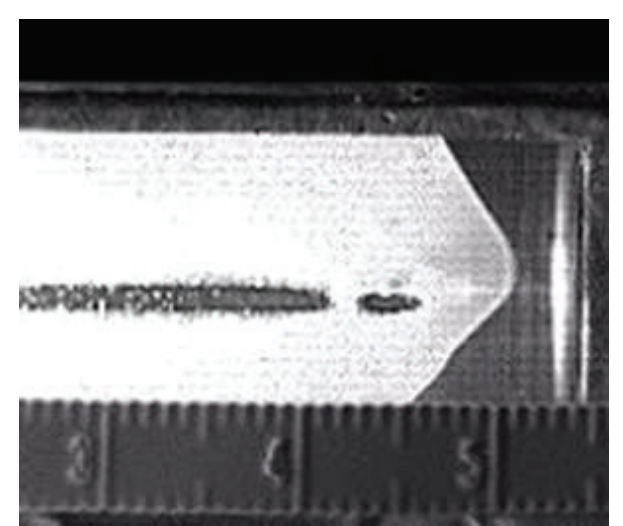

Fig. 9 Flame shape change at constriction (black stripes caused by overexposure of the camera sensor). 
higher pressure/density increases [47]. The increase in unburned gas density exceeds the decrease in laminar flame speed, thus the flame propagation speed is rising with higher ignition pressure.

Pressure and temperature data were collected during the test runs. Figs. 10 and 11 show the pressure respectively the temperature data during a test with an ignition pressure of 1 bar and no flashback arresting element mounted.

In this case the overpressure caused by the combustion in the closed vessel reaches 12 times the ignition pressure.

The pressure peak during the combustion process is very short, thus the thermocouples cannot resolve the temperature during the flame propagation. Additionally the position of the pressure transducers during the test with mounted windows (configuration A) was not ideal.

The compression of unburned gases and the time delay caused by the long connecting tubes distort the pressure values measured in the chamber. This was realized during later tests without the glass window (configuration B), when the sensors were mounted directly at a steel plate which replaced the glass window. Those tests resulted in a much better resolution of the pressure development inside the closed vessel.

To clarify the difference, compare e.g. the pressure course in Fig. 10 to the course in Fig. 14.

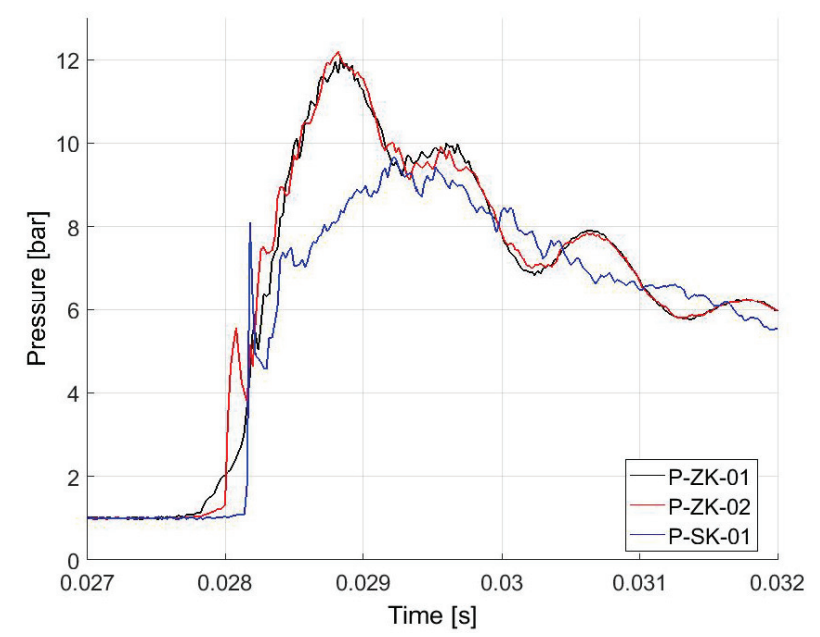

Fig. 10 Pressure course during ignition test without flashback arrester.

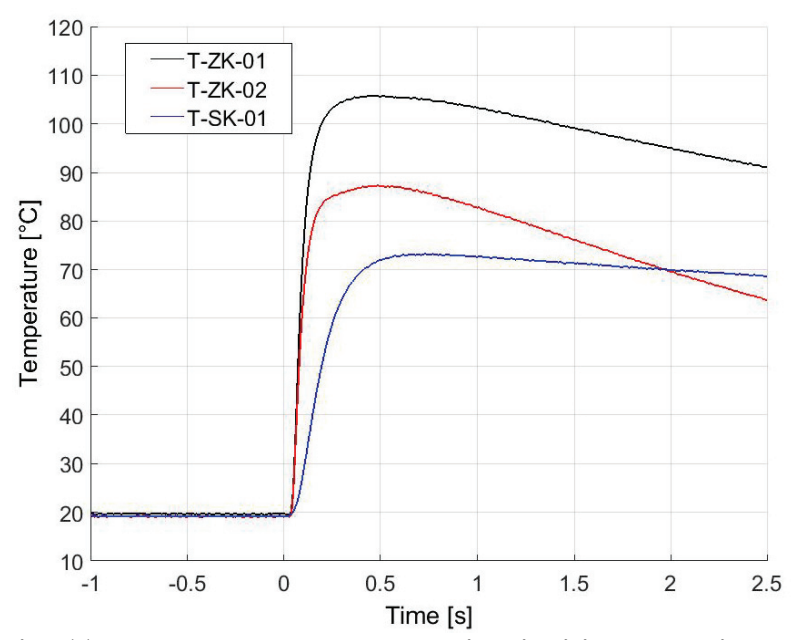

Fig. 11 Temperature course during ignition test without flashback arrester.

Nevertheless, Fig. 10 shows that the initial pressure rise is measured by P-ZK-01 which is positioned next to the spark plug. This peak is followed by a pressure increase at P-ZK-02 and finally the sensor in the flashback chamber measures the pressure rise (P-SK-01).

Regarding the thermocouples, the differences in the peak values are most likely caused by their position. The flashback chamber's volume to surface ratio is much lower than the ratio of the ignition chamber (diameter of the flashback chamber is $12.5 \mathrm{~mm}$ compared to $25 \mathrm{~mm}$ ). Thus a less amount of gas is burned in the flashback and the heat produced by the chemical reaction can easier be conducted to the chamber walls. This finally results in a lower maximum temperature measured by T-SK- 01 . The difference of T-ZK-01 and T-ZK-02 concerning the maximum temperature value might also be caused by their different positions. T-ZK-01 is located near the center of the ignition chamber; T-ZK-02 is placed near the constriction (the thermocouple tip can be seen in Fig. 13).

\subsection{Tests with Porous Materials as Flashback Arresters}

Subsequent to the tests without flashback arresting elements, combustion tests with porous material were conducted. At the beginning of each test series, the 


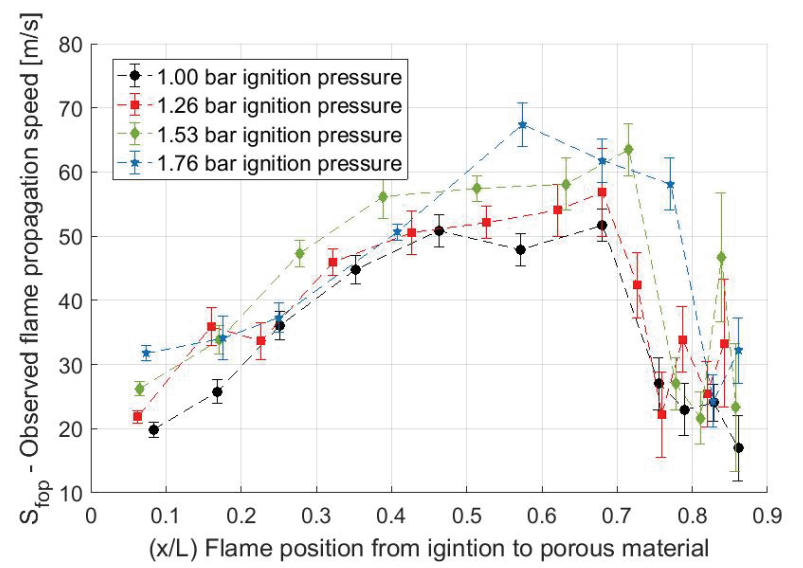

Fig. 12 Flame propagation speed with flashback arrester for different ignition pressures.

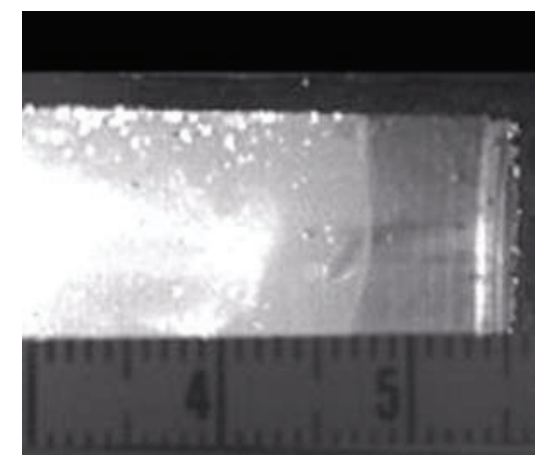

Fig. 13 Flame tip in front of flashback arrester.

ignition pressure was set to $1 \mathrm{bar}$ and successively raised until a flashback occurred. Up to a pressure of 1.8 bar the ignition and combustion process could be filmed via high speed camera (configuration A).

Pressure levels higher than 1.8 bar were conducted with steel plates mounted at the window's position on the ignition chamber (configuration B). Fig. 12 shows the flame propagation speed versus the flame position (measured from the ignition point, $x=0$ to the flashback arrester $x=L$ ) during the tests up to 1.76 bar.

In contrast to the above shown velocity without an arresting element mounted, the flame propagation speed develops differently:

(a) At the beginning, the flame propagates spherically, the acceleration seems to be linear.

(b) Approximately at $x / L=0.4$ the flame speed reaches a velocity plateau. This plateau is reached earlier than in those tests without flashback arresters.
The propagation of the flame and the expansion of the combustion products push the unburned gas to the front of the porous material. From the flames point of view the material behaves similar to a solid wall, the flow is stopped or strongly slowed down in front of the porous structure. Because the observed flame propagation is mainly caused by the flow field's velocity (see Eq. (2)), the flame velocity also drops.

(c) The flame propagation speed drops radically when the flame approaches the flashback arrester $(x / L$ $=0.7)$. As mentioned above, the porous material causes the flow to stop in front of the flashback arrester. In some cases the flame seems to accelerate again after slowing down. The videos of those cases show, that the flame front was pushed forward by rapidly expanding gases in the connection tubes of the ignition chamber (expansion of gases in venting lines, tubes to pressure transducers, etc.). It is assumed that the consumption speed of the flame increases strongly due to increasing flow speeds and a corresponding raise in turbulence in the connecting tubes. In some cases this might even cause a deflagration to DDT (detonation transition). So the combustible gas in those connections is consumed very quickly and pushes the flame in the main chamber forward. Furthermore pressure waves which are caused by the combustion and reflected by the chamber walls might push the flame forth and back.

The pressure data of the tests with mounted porous materials show different pressure courses and peaks compared to the pressure values observed during the test without flashback arresters. The authors assume the differences in the pressure course are caused by the change of the combustion chamber volume (from ignition and flashback chamber to ignition chamber only). Furthermore the change in the resolution of the pressure peaks itself is most likely influenced by the different position of the pressure sensors.

During the tests shown in Figs. 14 and 16 the pressure transducers of the ignition chamber were mounted at the steel plate (configuration B). 


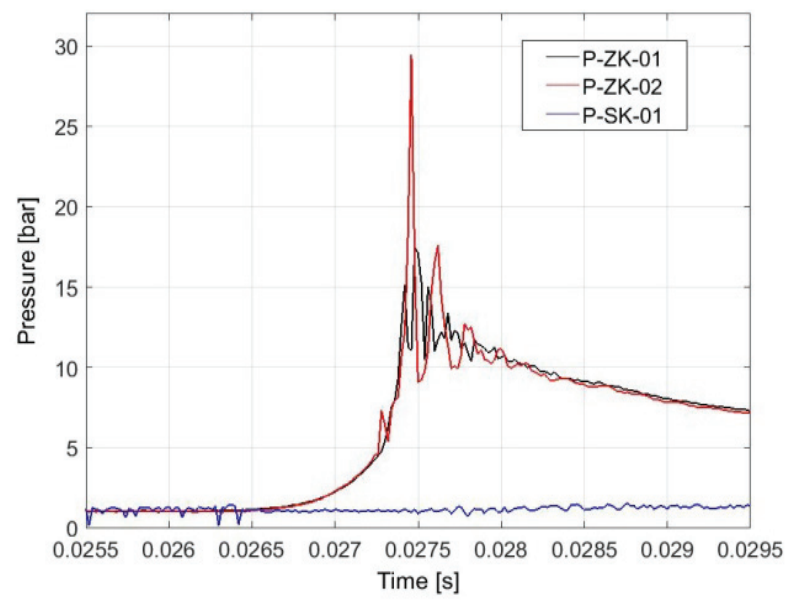

Fig. 14 Pressure in ignition and flashback chamber with porous material mounted-no flashback.

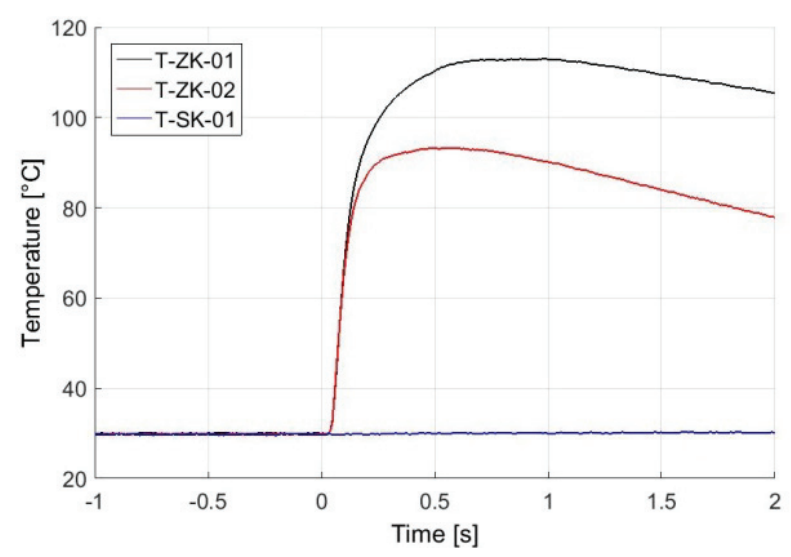

Fig. 15 Temperature data-no flashback.

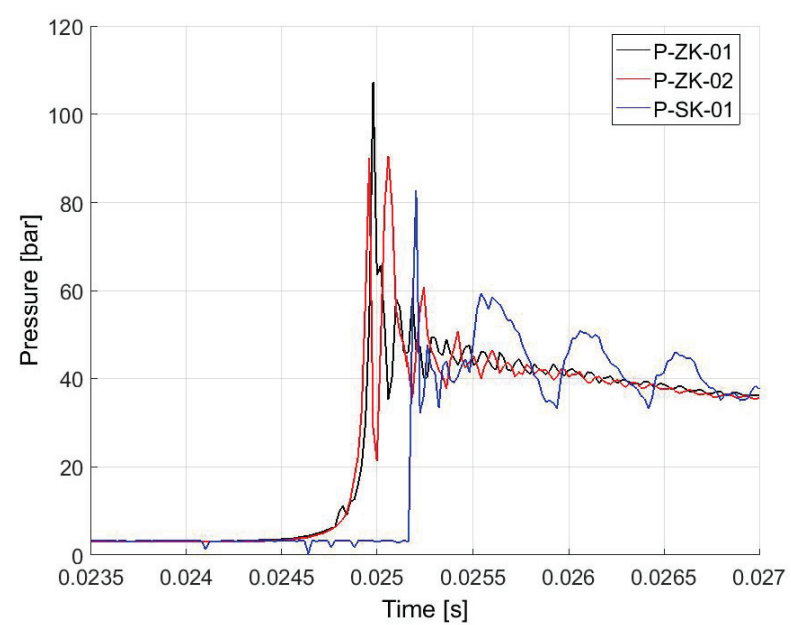

Fig. 16 Pressure in ignition and flashback chamber with porous material mounted-flashback.

Fig. 10 shows the pressure course for an ignition pressure of 1 bar and Fig. 14 shows the corresponding pressure course for a test with identical ignition pressure. Differences in the maximum pressure values are most likely caused by the sensor position. As mentioned before, the absolute value of the pressure is not very meaningful due to the shortness of the pressure peak.

Figs. 14 and 15 show the measurement data for a test where the flashback arrester worked properly and no flashback event was observed.

In comparison the data in Figs. 16 and 17 show a flashback event.

The sudden rise in temperature and pressure in the flashback chamber (blue lines in Figs. 16 and 17) is a clear indicator that a flame flashback did occur. The time scale in between the maximum pressure peak in the ignition chamber and the corresponding pressure maximum in the flashback chamber is in the range of $250 \mu \mathrm{s}$. Due to shortness of this time interval it is assumed that the flame directly propagates through the porous material and immediately lights the mixture on the upstream side of the flashback arrester. During all conducted tests in which flashback was observed, the time delay in between the pressure maxima in the ignition and flashback chamber was smaller than 500 $\mu \mathrm{s}$. In comparison, the pressure in the ignition chamber was higher than the pressure in the flashback chamber for up to $100 \mathrm{~ms}$ until the burned gas cooled down and the pressure in the ignition and flashback chamber leveled out. Comparing both time scales it seems to be most likely that flashback during the

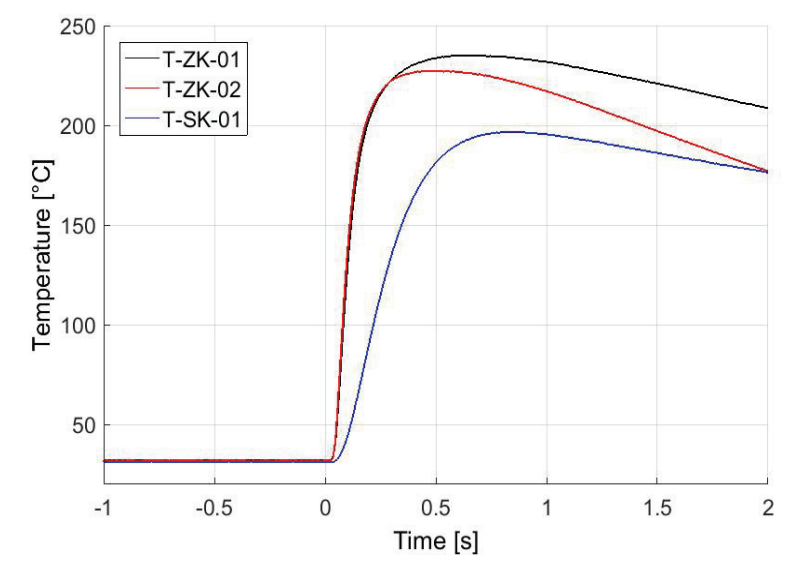

Fig. 17 Temperature data-flashback. 
observed cases is caused by direct flame propagation through the material. In all other cases where no flashback was observed, hot combusted gases flow through the flashback arrester for about $100 \mathrm{~ms}$ and no re-ignition did occur. This leads to the conclusion: If the porous material extracts enough heat from the flame to quench it, the material also cools the combusted gases below the ignition temperature of the unburned mixture.

\subsection{Peclet Numbers}

During the combustion test with porous materials, the ignition pressure was raised step by step until a flashback was observed. Due to the test setup and conditions, the minimum ignition pressure was ambient pressure. For several coarse materials (SIKA-B 200, SIKA-B 150, SIKA-B 100) an ignition pressure of 1 bar was sufficient to cause a flashback at the first test. A further restriction was given by the maximum ignition pressure. Increasing the static pressure above 4 bar and igniting the mixture resulted in a blow off of the graphite seals at the steel plates. Pressure peaks up to 150 bar were measured during those tests. Regarding flashback, the SIKA-R 200 materials in 10.5 and $21 \mathrm{~mm}$ length were able to avoid flashback for an ignition pressure of 4 bar. So the final conditions under which those materials fail could not be derived.

Fig. 18 shows the corresponding Peclet numbers. The numbers were calculated using the following equation:

$$
P e=\frac{d_{p} * S_{L}}{\alpha_{u}}
$$

Here $d_{p}$ is the pore diameter of the porous material as shown in Table 1. As described above, the laminar flame speed $S_{\mathrm{L}}$ was calculated via a Cantera [23] and a reaction mechanism derived by DLRs Institute of Combustion Technology [46].

The thermal diffusivity for the unburned mixture $\rho_{u}$ was obtained from Refprop database [39] assuming the mixture ratio which resulted from the gas sample analysis via gas chromatography.

Fig. 18 and Table 2 show the derived Peclet numbers for the tested materials. The Peclet number for "no flashback" was the largest number achieved during the tests where no flashback occurred with the tested material. Correspondingly the "flashback" Peclet number was the smallest Peclet number where flashback occurred. For the SIKA-B 200 and B 150 materials, the pressure could not be reduced enough to achieve a Peclet number where no flashback occurred. The flame passed the material at an ignition pressure of 1 bar. For the SIKA-B 30, the R 200 with $21 \mathrm{~mm}$ length and the R 200 with $10.5 \mathrm{~mm}$ length, the Peclet number under which flashback occurs, could not be derived. For those materials the ignition pressure could not be raised high enough to observe flashback. For the two other samples (SIKA-B $10021 \mathrm{~mm}$ length and SIKA-R $2007 \mathrm{~mm}$ length) the upper and lower range of the Peclet numbers could be approximated. Due to damage at the sealing, the Peclet number for the SIKA-R 200 material in $7 \mathrm{~mm}$ length could not be localized in detail. The upwards facing triangles in the diagram show the maximum Peclet number at which no flashback occurred. The downwards facing triangles mark the Peclet number at which flashback occurred.

Table 2 Tested materials, maximum Peclet numbers for no flashback and minimum Peclet numbers for flashback.

\begin{tabular}{lllll}
\hline Sample & Length $(\mathrm{mm})$ & Pore size $(\mathrm{mm})$ & Pe. no flashback & $P e$. flashback \\
\hline SIKA-B 200 & 21 & 0.573 & Not achieved & 54.98 \\
SIKA-B 150 & 21 & 0.344 & Not achieved & 32.33 \\
SIKA-B 150 & 10.5 & 0.344 & Not achieved & 32.08 \\
SIKA-B 100 & 21 & 0.232 & 21.93 & 26.02 \\
SIKA-B 30 & 10.5 & 0.066 & 20.55 & Not achieved \\
SIKA-R 200 & 21 & 0.286 & 91.40 & Not achieved \\
SIKA-R 200 & 10.5 & 0.286 & 90.88 & Not achieved \\
SIKA-R 200 & 7 & 0.286 & 49.71 & 71.02 \\
\hline
\end{tabular}




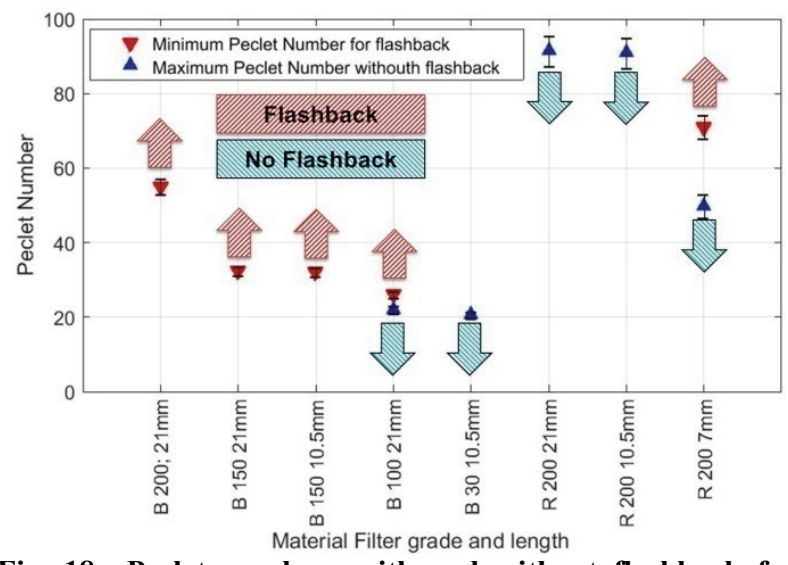

Fig. 18 Peclet numbers with and without flashback for investigated porous materials.

Although the upper and lower limits of the Peclet numbers could not be derived for all materials, general trends and limitations are visible.

(a) The porous sintered bronze material (SIKA-B) seems to allow the flame passing at significantly lower Peclet numbers. In the same range of pore diameters, the sintered bronze seems not to be able to prohibit a flashback as good as the sintered stainless steel. The considerable smaller quenching Peclet number may be caused by catalytic effects of the copper based bronze material. From literature [48] it is known, that copper can support the decomposition of $\mathrm{N}_{2} \mathrm{O}$. Furthermore the structure (e.g. the tortuosity) of the sintered bronze material (SIKA-B) is completely different from the sintered stainless steel material (SIKA-R) (see Fig. 6). This difference in internal structure of the material will most likely affect the flow of the reacting gases through the porous material.

The more chaotic structure of the sintered stainless steel might increase turbulence in the material, this can lead to an improved heat flux from the flame front to the materials walls.

(b) Despite the analytic derivation of the quenching diameter, the length of the quenching channel seems to have an influence on the flashback behavior. The shorter SIKA-R 200 material quenches the flame not as efficient as the longer materials (e.g. compare the flashback Peclet numbers of R $2007 \mathrm{~mm}$ to R 200 $10.5 \mathrm{~mm}$ ). Due to the complex structure of the porous materials it may also be possible, that in a longer material smaller pores are more likely to exist. However the length seems to have a significant influence on the critical Peclet number. Regarding literature [49] a proper flashback arrester needs to have an effective passageway length to quench the flame definitely.

An empirical correlation for designing flashback arresters is given by Ref. [49]:

$$
L>2 * S_{t} * d_{q}
$$

Here $L$ marks the flame arresters passageway length, $S_{t}$ is the turbulent flame speed and $d_{q}$ the quenching diameter of the passageway. The unit for $L$ and $d_{q}$ is $\mathrm{cm}$, while the flame speed is in $\mathrm{m} / \mathrm{s}$. Because the SIKA-R 200 material shows an influence of the flashback behavior depending on the length, Eq. (13) is used taking the pore size of the SIKA-R 200 material as $d_{q}$. Furthermore a conservative estimation of the flame propagation speed is made. It is assumed that the turbulent flame speed in Eq. (13) corresponds to the flame propagation speed observed during the conducted tests. With a rough approximation of $S_{t}=$ $100 \mathrm{~m} / \mathrm{s}$ and $d_{q}=0.0286 \mathrm{~cm}, L$ should be larger than $0.164 \mathrm{~cm}$. The materials length is $0.7 \mathrm{~cm}$, thus it should definitely quench the flame. Compared to the SIKA-B material, the more complex pore structure of the SIKA-R material possibly enhances the ability to avoid a flame flashback. Due to non-uniform pore structure of the SIKA-R material, the pressure drop of those materials is also higher than the pressure drop of the SIKA-B material. Furthermore, the pressure drop across the material might influence the quenching Peclet number as well. It is thinkable that an increased pressure drop across the materials results in a larger quenching diameter.

\subsection{Errors and Deviations}

Different errors are assumed or were determined for the results of the Peclet numbers, for the pressure and 
temperature data as well as for the flame propagation speed.

First the error of the flame propagation speed is examined. Due to the uncertainty of the correct pixel position and the manual determination of the flame front's position, an average error of $0.3 \mathrm{~mm}$ on the flame tip position was assumed.

This error affects mainly the derived flame propagation speed during high velocities (small time steps) and results in the error bars shown in Figs. 8 and 12. For the cases of high velocities, the time step in between two positions $\Delta x$ gets smaller. Because $S_{\text {ofp }}$ $=\Delta x / \Delta t$, for small time steps $\Delta t$, the error of $\Delta x$ plays a larger role.

Further on, the measurement data of the pressure sensors were compared to a calibrated reference device equipped with a Beamex EXT 250 pressure module. The thermocouple data were compared to the values of a calibrated Beamex FB660 Field Temperature Block. The maximum deviation of one of the pressure sensors in the investigated range was $2.35 \%$; the maximum error of the Typ-K thermocouples was $2 \%$.

The laminar flame speed calculation done with the optimized reaction mechanism [46] and the Cantera software toolkit [23] was assumed to be in a 5\% range to the measured flame speeds. Those deviations of the flame speed caused the main part of the error bar in the Peclet number diagram (Fig. 18). For the deviation of the pore size diameter, the data sheet of the manufacturer [40] was considered. The used standard [41] for determination of the pore size gives an error of $5 \%$ on the average pore size.

To control and analyze the mixture ratio during the test campaign, gas samples of the combustible mixture were taken at the beginning and at the end of a test series. The maximum number of tests during a test series was restricted by the available gas mass in the mixing vessel. The gas samples were analyzed via gas chromatography, the results are shown in Fig. 19. The average mixture ratio was $\phi=0.9$, while one mixture

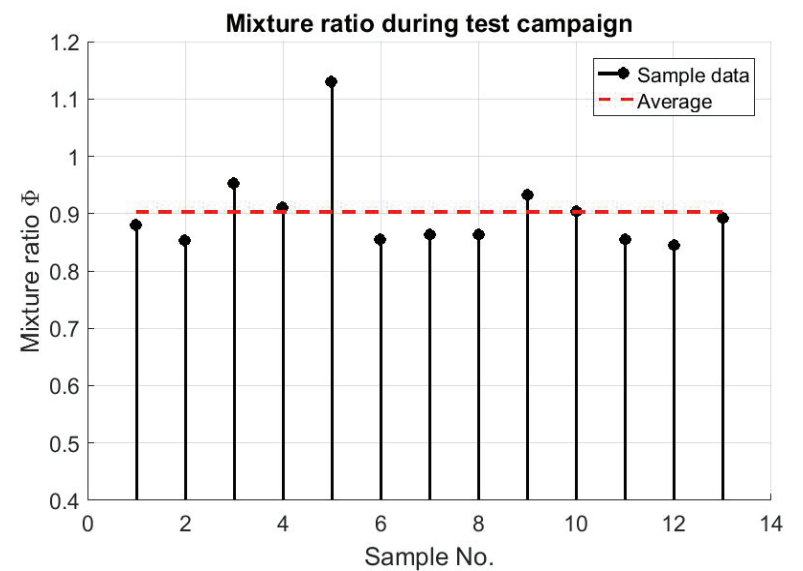

Fig. 19 Gas samples during test campaign.

(Sample No. 5) had a rich composition. To avoid errors caused by different flame speeds and thermal diffusivities, for calculation of the Peclet number the mixture ratio analyzed by the gas sampling was taken into account.

\section{Summary and Outlook}

Combustion and ignition tests with a gaseous mixture of $\mathrm{N}_{2} \mathrm{O}$ (dinitrogen monoxide) and $\mathrm{C}_{2} \mathrm{H}_{4}$ (ethylene) with a mixture ratio around $\phi=0.9$ were conducted. The mixture was ignited via spark plug in a closed volume. The test setup consisted of two chambers: an ignition chamber and a flashback chamber. In between the two chambers flashback arresting porous materials could be mounted. The ignition chamber can be equipped with a quartz glass window to observe the flame propagation under different test conditions. The ignition and flame propagation was filmed for test cases with and without porous materials by a high speed camera. The high speed imaging data were used to derive the observed flame propagation speed $\left(S_{\text {ofp }}\right)$. This velocity results from the laminar flame speed $S_{\mathrm{L}}$ and the expansion speed $S_{\text {exp }}$ of the burned gases. During the experiments, different phases of the flame propagation could be observed. Shortly after ignition the propagation speed was in the range of $20 \mathrm{~m} / \mathrm{s}$, followed by an acceleration of the flame where propagation speeds of up to $120 \mathrm{~m} / \mathrm{s}$ were observed. 
Furthermore pressure and temperature readings were taken during the ignition and flame propagation process. The pressure and temperature data were used to determine if a flashback from the ignition into the flashback chamber occurred during the tests with porous materials. For the flashback tests, the ignition pressure was raised from test to test until a sharp rise in pressure and temperature in the flashback chamber was observed. Furthermore, Peclet numbers were calculated for the used sintered stainless steel materials (SIKA-R) and the sintered bronze materials (SIKA-B). To calculate the Peclet number the porous material's pore size, the laminar flame speed obtained from optimized reaction mechanisms and the thermal diffusivity from Refprop database were used. For the tested SIKA-B material the critical Peclet number for occurrence of flashback is below 20, apart from one sample for which the ignition chamber pressure could not increase up to the flashback limit. The tests with SIKA-R material show critical Peclet numbers above 40.

In general two phenomena were observed:

First, the quenching ability of the porous materials seems to depend on the length of the material. For the $7 \mathrm{~mm}$ long SIKA-R 200 material, the critical Peclet number was above 40 , for the $10.5 \mathrm{~mm}$ long SIKA-R 200 material, the critical Peclet number is above 80 .

Second, the sintered bronze SIKA-B materials prohibit a flashback not as sufficient as the sintered stainless steel materials with comparable pore size. The "no flashback" Peclet numbers for the bronze material are in between $1 / 2$ to $1 / 4$ of the numbers for the stainless steel material. The difference in between the two materials might: (a) be caused by catalytic effects of the bronze material or (b) be caused by differences in the internal structure of the material (e.g. by a different pore size distribution, by different pore lengths, different tortuosity or by a different roughness of the material's walls).

For future tests the following modifications at the test setup are planned:
The range of pressure levels will be extended, thus also sub atmospheric pressure tests will be conducted. The pressure transducers will be mounted directly at the combustion chamber walls. To investigate flame flashback at higher pressure levels, the chamber should be reconstructed, the sealing concept will also be rethought. For better comparability, capillary tubes with a defined diameter will be tested and the resulting Peclet numbers will be compared to the ones obtained from the used porous materials.

\section{Acknowledgments}

The authors would like to thank the M11 test bench team for the support in preparing and conducting the tests. Furthermore the help of the colleagues from the DLR Institute of Combustion Technology, Torsten Methling and Clemens Naumann is greatly acknowledged. The work described in this paper was conducted in the framework of DLR's Future Fuels project.

\section{References}

[1] Sutton, G. P., and Biblarz, O. 2010. Rocket Propulsion Elements. New York: John Wiley \& Sons.

[2] Space.com. At Solar System's Edge, Old Voyager 1 Probe Performs "New Acrobatics". [Online] Accessed on May 20, 2017. Available at: http://www.space.com/11087-nasa-voyager-1-acrobaticssolar-system.html.

[3] Landau, E. 2017. Voyager 1 Fires up Thrusters after 37 Years. [Online] Accessed on Dec. 03, 2017. Available at: https://www.nasa.gov/feature/jpl/voyager-1-fires-up-thrus ters-after-37.

[4] European Chemicals Agency. 2017. Candidate List of Substances of Very High Concern for Authorisation: Published in Accordance with Article 59(10) of the REACH Regulation. [Online] Accessed on: May 20, 2017. Available at: http://echa.europa.eu/en/candidate-list-table.

[5] Bombelli, V., Simon, D., Moerel, J.-L., and Marée, T. 2003. "Economic Benefits of the Use of Non-toxic Mono-Propellants for Spacecraft Applications.” Present at the 39th AIAA/ASME/SAE/ASEE Joint Propulsion Conference, 20-23 July 2003, Huntsville, Alabama, USA.

[6] Ferran, V.-B., and Smith, M. 2012. "Replacement of Conventional Spacecraft Propellants with Green Propellants." Present at Space Propulsion Conference, 7-10 May 2012, Bordeaux, France. 
[7] Gohardani, A. S., Stanojev, J., Demairé, A., Anflo, K., Persson, M., Wingborg, N., et al. 2014. "Green Space Propulsion: Opportunities and Prospects." Progress in Aerospace Sciences 71 (8): 128-49.

[8] Anflo, K., and Crowe, B. 2011. "Two Years of In-space Demonstration and Qualification of an ADN-Based Propulsion System on PRISMA." Present at the 47th AIAA/ASME/SAE/ASEE Joint Propulsion Conference, 31 July-03 August 2011, San Diego, California, USA.

[9] Anflo, K., and Möllerberg, R. 2009. "Flight Demonstration of New Thruster and Green Propellant Technology on the PRISMA Satellite." Acta Astronautica 65 (9-10): 1238-49.

[10] Negri, M. 2015. "Replacement of Hydrazine: Overview and First Results of the H2020 Project Rheform." Present at the 6th European Conference for Aeronautics and Space Sciences (EUCASS), 29.06-03.07.2015, Krakow, Poland.

[11] Katsumi, T., Inoue, T., Nakatsuka, J., Hasegawa, K., Kobayashi, K., Sawai, S., et al. 2012. "HAN-Based Green Propellant, Application, and Its Combustion Mechanism." Combust Explos Shock Waves 48 (5): 536-43.

[12] Azuma, N., Hori, K., Katsumi, T., Amrousse, R., Nagata, T., Hatai, K., et al. 2013. "Research and Development on Thrusters with HAN (Hydroxyl Ammonium Nitrate) Based Monopropellant." Present at the 5th European Conference for Aeronautics and Space Sciences, 1-5 July 2013, Munich, Germany.

[13] Lillard, R. 2017. "Technology Demonstration Missions Program: NASA Presentation." [Online] Accessed on June $02, \quad 2017 . \quad$ Available at: https://www.nasa.gov/sites/default/files/files/RLillard.pdf

[14] Jankovsky, R. S. "HAN-Based Monopropellants Assessment for Spacecraft: NASA Technical Memorandum 107287." AIAA-96-2863, NASA.

[15] Božić, O., Porrmann, D., Lancelle, D., and May, S. 2016. "Enhanced Development of a Catalyst Chamber for the Decomposition of up to $1.0 \mathrm{~kg} / \mathrm{s}$ Hydrogen Peroxide." CEAS Space Journal 8 (2): 77-88. http://dx.doi.org/10.1007/s12567-015-0109-x, 2016.

[16] Cervone, A., Torre, L., D’Agostino, L., Musker, A. J., Roberts, G. T., Bramanti, C., et al. 2006. "Development of Hydrogen Peroxide Monopropellant Rockets.” Present at the 42nd AIAA/ASME/SAE/ASEE Joint Propulsion Conference \& Exhibit, 9-12 July 2006, Sacramento, California, USA.

[17] Gotzig, U., Krauss, S., Welberg, D., Fiot, D., Michaud, P., Desaguier, C., et al. 2015. "Development and Test of a 3D Printed Hydrogen Peroxide Flight Control Thruster." Present at the 51st AIAA/SAE/ASEE Joint Propulsion
Conference, July 27-29, 2015, Orlando, Florida, USA.

[18] Ventura, M., Wernimont, E. J., Heister, S., and Yuan, S. 2011. "Rocket Grade Hydrogen Peroxide (RGHP) for Use in Propulsion and Power Devices-Historical Discussion of Hazards." Present at the 47th AIAA/ASME/SAE/ASEE Joint Propulsion Conference, July 31-August 03 , 2011, San Diego, California, USA.

[19] Mungas, G., Vozoff, M., and Rishikof, B. 2012. "NOFBX: A New Non-toxic, Green Propulsion Technology with High Performance and Low Cost." Present at the 63rd International Astronautical Congress, October 1-5, 2012, Naples, Italy.

[20] Werling, L., Perakis, N., Müller, S., Hauck, A., Ciezki, H., and Schlechtriem, S. 2016. "Hot Firing of a $\mathrm{N}_{2} \mathrm{O} / \mathrm{C}_{2} \mathrm{H}_{4}$ Premixed Green Propellant: First Combustion Tests and Results.” Present at Space Propulsion Conference, May 1-5, 2016, Rome, Italy.

[21] Werling, L., Hassler, M., Lauck, F., Ciezki, H. K., and Schlechtriem, S. 2017. "Experimental Performance Analysis (c* \& c* Efficiency) of a Premixed Green Propellant Consisting of $\mathrm{N}_{2} \mathrm{O}$ and $\mathrm{C}_{2} \mathrm{H}_{4}$." Present at AIAA Propulsion and Energy Forum, the 53rd AIAA/SAE/ASEE Joint Propulsion Conference: American Institute of Aeronautics and Astronautics.

[22] Weast, R. C., Hogman, C. D., and Veazey, W. R. 2013. CRC Handbook of Chemistry and Physics: A Ready-Reference Book of Chemical and Physical Data. 94th ed. Boca Raton, FL: CRC Press.

[23] Goodwin, D. G., Moffat, H. K., and Speth, R. L. 2016. Cantera: An Object-Oriented Software Toolkit for Chemical Kinetics, Thermodynamics, and Transport Processes.

[24] Smith, G. P., Golden, D. M., Frenklach, M., Moriarty, N. W., Eiteneer, B., Goldenberg, M., et al. GRI-Mech 3.0. [Online] Available at: http://www.me.berkeley.edu/gri_mech/.

[25] Naumann, C., Kick, T., Methling, T., Braun-Unkhoff, M., and Riedel, U. 2017. "Ethene/Dinitrogen Oxide-A Green Propellant to Substitute Hydrazine: Investigation on Its Ignition Delay Time and Laminar Flame Speed." Present at the 26th International Colloquium on the Dynamics of Explosions and Reactive Systems, July 30-August 4, 2017, Boston, USA.

[26] Peters, N. 1992. Fifteen Lectures on Laminar and Turbulent Combustion: Ercoftac Summer School. September 14-28, 1992, Aachen Germany.

[27] Faghih, M., and Chen, Z. 2016. "The Constant-Volume Propagating Spherical Flame Method for Laminar Flame Speed Measurement." Science Bulletin 61 (16): 1296-310.

[28] Kuo, K. K. 2005. Principles of Combustion (2nd ed.). Hoboken, NJ: Wiley. 
[29] Turns, S. R. 2000. An Introduction to Combustion: Concepts and Applications (2nd ed.). Boston: McGraw-Hill.

[30] Bellenoue, M., Kageyama, T., Labuda, S. A., and Sotton, J. 2003. "Direct Measurement of Laminar Flame Quenching Distance in a Closed Vessel." Experimental Thermal and Fluid Science 27 (3): 323-31.

[31] Boust, B., Sotton, J., Labuda, S. A., and Bellenoue, M. 2007. "A Thermal Formulation for Single-Wall Quenching of Transient Laminar Flames." Combustion and Flame 149 (3): 286-94.

[32] Ferguson, C. R., and Keck, J. C. 1977. "On Laminar Flame Quenching and Its Application to Spark Ignition Engines." Combustion and Flame 28 (December): 197-205.

[33] Jarosiński, J. 1983. "Flame Quenching by a Cold Wall." Combustion and Flame 50 (2): 167-75.

[34] Daou, J., and Matalon, M. 2002. "Influence of Conductive Heat-Losses on the Propagation of Premixed Flames in Channels." Combustion and Flame 128 (4): 321-39.

[35] Spalding, D. B. 1957. "A Theory of Inflammability Limits and Flame-Quenching." Proceedings of the Royal Society of London A: Mathematical, Physical and Engineering Sciences 240 (1220): 83-100.

[36] Ciccarelli, G. 2012. "Explosion Propagation in Inert Porous Media." (Eng.) Philosophical Transactions. Series A: Mathematical, Physical, and Engineering Sciences 370: 647-67.

[37] Joo, H. I., Duncan, K., and Ciccarelli, G. 2006. "Flame-Quenching Performance of Ceramic Foam." Combustion Science and Technology 178 (10-11): 1755-69.

[38] Jarosinsky, J., and Veyssiere, B. 2009. Combustion Phenomena: Selected Mechanisms of Flame Formation, Propagation, and Extinction. Boca Raton: CRC Press.

[39] Lemmon, E. W., Huber, M. L., and McLinden, M. O. 2013. NIST Standard Reference Database 23: Reference Fluid Thermodynamic and Transport Properties-REFPROP. Gaithersburg: National Institute of Standards and Technology.
[40] GKN Sinter Metals. 2016. Filter-Elements High Porosity Sintered Parts SIKA-R...AX and SIKA-B. [Online] Accessed on June 19 2016. Available at: www.gkn-filters.de/downloads/pdf/download.php?filena me=sika-r-ax-sika-b.pdf.

[41] 1990. Durchlässige Sintermetalle Ermittlung der Porengröße Mittels Gasblasentest, DIN/ISO 4003: 1990-10.

[42] Werling, L., Müller, S., Hauk, A., Ciezki, H., and Schlechtriem, S. 2016. "Pressure Drop Measurement of Porous Materials: Flashback Arrestors for a $\mathrm{N}_{2} \mathrm{O} / \mathrm{C}_{2} \mathrm{H}_{4}$ Premixed Green Propellant." Present at 52nd AIAA/SAE/ASME Joint Propulsion Conference, 25-27 July, Salt Lake City, Utah, USA.

[43] Clanet, C., and Searby, G. 1996. "On the 'Tulip Flame' Phenomenon." Combustion and Flame 105 (1): 225-38.

[44] Starke, R., and Roth, P. 1986. "An Experimental Investigation of Flame Behavior during Cylindrical Vessel Explosions." Combustion and Flame 66 (3): 249-59.

[45] Starke, R., and Roth, P. 1989. "An Experimental Investigation of Flame Behavior during Explosions in Cylindrical Enclosures with Obstacles." Combustion and Flame 75 (2): 111-21.

[46] Kick, T., Starcke, J. H., and Naumann, C. 2017. "Green Propellant Substituting Hydrazine: Investigation of Ignition Delay Time and Laminar Flame Speed of Ethene/Dinitrogen Oxide Mixtures." Present at the 8th European Combustion Meeting, 18-21 April 2017, Dubrovnik, Croatia.

[47] Glassman, I., Yetter, R. A., Glassman, I., Glumac, N., and Yetter, R. A. 2008. Combustion. Amsterdam: Elsevier, Academic Press.

[48] Scholten, J. J. F., and Konvalinka, J. A. 1969. "Reaction of Nitrous Oxide with Copper Surfaces. Application to the Determination of Free-Copper Surface Areas." Transactions of the Faraday Society 65: 2465-73.

[49] Grossel, S. S. 2002. Deflagration and Detonation Flame Arresters. New York: Center for Chemical Process Safety of the American Institute of Chemical Engineers. 